might free the obstetrician from the unwanted attention of the lawyers in these matters.

Professor of Obstetrics and Gynaecology,

E M SYMONDS

University Hospital,

Nottingham NG7 2UH

1 Brown JK. Infants damaged during birth: pathology. In: Hall D, ed. Recent advances in paediatrics. New York: Churchill Livingstone, 1976:35-88.

2 Dweck $H$, Huggins $W$, Dorman $L$, et al. Developmental sequelae in infants having severe perinatal asphyxia. Am f Obstet Gynecol 1974;119:811.

Nelson KB, Ellenberg JH. Antecedents of cerebral palsy. N Engl f Med 1986;315:81-6.

\section{Screening for congenital dislocation of the hip}

Unlike many examinations carried out in child health surveillance programmes, screening for congenital dislocation of the hip cannot be said to be unresearched. A selective Medline search provided over 100 papers on the screening, diagnosis, and management of the condition. From the past six years they show that the early identification of the 15-20 children in 1000 at high risk of having instability and subluxation, dysplasia, or both, of the hip joint is of great benefit to the two to four (and perhaps more) of them who would go on to suffer the long term consequences if not treated. Workers dedicated to identifying congenital dislocation of the hip who have good back up services can identify $80-90 \%$ of all the cases in the population in the first six weeks of life. Under these conditions the selectivity, sensitivity, and cost effectiveness of the test are acceptableanything less and the programmes fail. ${ }^{2}$ So the important question is not whether to set up a screening programme but how to set up one that is effective.

This important question has been partly answered by a revised version of the government handbook Screening for the Detection of Congenital Dislocation of the Hip. ${ }^{3}$ It is an excellent review of current thinking, and a doctor ignores it at his peril. The handbook is concerned only with screening and offers no advice on management. It is directed specifically at those organising and running child health surveillance programmes and those carrying them outmidwives, paediatricians, obstetricians, health visitors, general practitioners, and clinical medical officers. More's the pity that all these groups did not receive a free copy: it went to most of the doctors but not to most of the nurses. Why not?

The most important section is on who should do the screening. The district health authority should have a policy outlining who is responsible for examining for congenital dislocation of the hip at various stages and should appoint a designated officer to review the whole programme. Several health professionals may at some time have to examine a child's hips, and they should all be proficient-therefore training is crucially important.

The handbook discusses future developments; and ultrasound may well be used much more in diagnosis. It looks good from the little research done so far, especially as it is non-invasive and its results are sensitive. Also clinically normal but dysplastic hips do probably exist, and ultrasound may be able to detect them. ${ }^{4}$ Further research must therefore be funded into using ultrasound both for initial screening and for secondary screening of those children already identified as being at high risk. These would include those with a clicking or dislocatable hip and those with some other risk factor such as a family history of the condition, other congenital postural deformities, or a history of breech presentation, caesarean delivery, oligohydramnios, or severe fetal growth retardation.

For now, however, the screening programme for congenital dislocation of the hip must be that outlined in the handbook, and the next step has to be taken by those responsible for the child health surveillance programmes in the districts. If the suggestions are not already operational and they do not intend to make them so but have the funding they will need to think up a good excuse rapidly.

AIDAN MACFARLANE

Consultant Paediatrician with special interest in

community child health and Clinical Lecturer in Paediatrics, District Department of Community Medicine,

Radcliffe Infirmary,

Oxford OX2 6HE

1 Dunn PM. Screening for congenital dislocation of the hip. In: Macfarlane A, ed. Progress in child health. Vol 3. London: Churchill Livingstone, 1986:1-12.

Hanssen G, Nachemson S, Palmen K. Screening of children with congenital dislocation of the hip Hanssen G, Nachemson S, Palmen K. Screening of children with congenita
joint on the maternity wards in Sweden. J Pediatr Orthop 1983;3:271-9.

3 Standing Medical Advisory Committee and Standing Nursing and Midwifery Advisory Committee for the Secretaries of State for Social Services and $W$ ales. Screening for the detection of congenital for the Secretaries of State for Social Services and Wales. Screening for the detection

4 Berman L, Klenerman L. Ultrasound screening for hip abnormalities: preliminary findings in 1001 neonates. BrMed J 1986;293:719-22.

\section{More evidence on unemployment and health}

Most of those who have studied the future of employment agree that whichever political party is in power the total amount of employment is going progressively to diminish. ${ }^{12}$ A generation ago people expected to be employed over a lifetime for 100000 hours (47 hours a week for 47 weeks a year for 47 years), but already it is down to 50000 hours (37 hours a week for 37 weeks a year for 37 years). Soon it will be less. This means that we either share out more the employment available or we have an ever growing number of unemployed. It also means that unemployment is not going to be spirited away by either a statistical or a political sleight of hand. Researchers therefore need to continue to w/: rk to increase our limited understanding of how unemployment affects health, and health workers and health authorities need to think more creatively about how they can respond to the problem. Three papers that we publish this week and one that we published earlier in the year should help.

The earlier paper by Moser et al (10 January, p 86) has not had the attention that it deserves. Their earlier study from the 1971 census had shown that men seeking work at the time of the census had had a significantly higher mortality over the next 10 years than men in work. ${ }^{3}$. The authors were confident that the excess mortality was caused by unemployment itself and had not arisen simply because sick men were more likely to be unemployed. But in 1971 unemployment was well under a million in Britain, and the authors warned that it would be wrong to extrapolate their findings to now when unemployment is around three million. It was in 1979 that unemployment began to rise very steeply in Britain, and by 1981 the figure was similar to that now. Thus the author's new findings that their results from the 1981 census are 